\title{
Photocatalytic oxidation of organic contaminants in water: An aid to environmental preservation
}

\author{
Ralph W. Matthews \\ CSIRO, Division of Coal \& Energy Technology, Lucas Heights Research Laboratories, \\ PMB 7, Menai, NSW 2234, Australia
}

\begin{abstract}
The advantages of photocatalytic oxidation with titanium dioxide over conventional photochemical oxidations include the longer wavelength of the exciting wavelength (up to $380 \mathrm{~nm}$ ) and the fact that no expensive oxidizing chemicals are consumed; atmospheric oxygen is the oxidant. Disadvantages include low photon efficiencies of the oxidation and long settling times with ultrafine catalysts. The latter can be avoided by using immobilized catalysts but oxidation rates are less than with free suspensions. The rates of phenol degradation and mineralization with various electrically-powered and, solar-powered light sources are given using catalysts in free suspension and immobilized. The utility of a new photocatalytic total organic carbon analyzer in environmental preservation is discussed.
\end{abstract}

\section{INTRODUCTION}

Few regions on earth have abundant supplies of pure water. These locations are generally remote from intensive human activities because of climatic or topographic deterrents. Other locations with plentiful high quality water supplies have long been intensively developed. This development has resulted in a progressive deterioration of water quality in many places to the extent that water supplies formerly of good quality are now potentially hazardous to human health. It is essential that further pollution be prevented and that controls be introduced or enforced to curtail avoidable pollution and to minimize the risk of accidental pollution. The challenge is to seek the most economical, effective means of doing this. Therefore, stricter controls on the discharge and storage of polluted effluents is an integral part of environmental preservation strategy along with a thorough investigation of new water treatment processes and efforts to improve existing water treatment technologies.

The removal of organic pollution from water supplies has traditionally been effected by adsorption with activated carbon. However, some pollutants are poorly or not adsorbed by activated carbon and where adsorption is efficient the transfer of the pollutant from the aqueous to the solid phase does not provide a permanent removal of the hazard. The carbon must then be either regenerated or incinerated by some means which converts the adsorbed pollutant to totally innocuous products. In view of the formation of toxic, stable products such as dioxins, in some high temperature processes [1] this may not always be easily ensured. For this reason attention is being given to alternative destructive oxidation processes for water treatment, frequently referred to as advanced oxidation processes.

The object of destructive oxidation processes is to mineralize organic contaminants, ie., convert them to carbon dioxide, water and the oxidised inorganic anions of any heteroatoms present. These processes frequently include the addition of oxidizing agents such as hydrogen peroxide and ozone in the presence of a catalyst or UV light. Hydroxyl radicals are known to be involved in most of these processes. Examples include $U V / \mathrm{H}_{2} \mathrm{O}_{2}$, Fenton's Reagent, $\mathrm{UV} / \mathrm{O}_{3}, \mathrm{H}_{2} \mathrm{O}_{2} / \mathrm{O}_{3}, \mathrm{O}_{3} / \mathrm{pH}$, high energy radiation and photocatalytic oxidation (PCO).

Because the application of PCO to water treatment is a comparatively recent development and because it offers certain advantages over the preceding oxidation processes it will be the main subject of this paper. The advantages include:

1) there is no consumption of expensive oxidizing chemicals; the oxidant is atmospheric oxygen and the catalyst is non-hazardous.

2) the light required to activate the catalyst may be long wavelength UV transmitted by glass.

3) the photocatalytic reaction may be driven by the natural UV component of sunlight.

4) the oxidation is powerful and indiscriminate leading to the mineralization of the majority of organic pollutants; exceptions are compounds which are resistant to $\mathrm{OH}$ radical attack such as carbon tetrachloride and cyanuric acid. 
Much work has been undertaken in recent years in studying the PCO of many classes of organic compounds, especially priority pollutants, with attention to the identification of intermediate degradation products. Excellent reviews have recently been published[2,3]. Titanium dioxide is the most commonly used photocatalyst because certain forms have reasonable photo-activity and it is non-toxic, insoluble and comparatively inexpensive. In this paper, the results discussed were obtained exclusively with Degussa P25 titanium dioxide which has a B.E.T. surface area of $50 \mathrm{~m}^{2} / \mathrm{g}$, a primary particle size of $30 \mathrm{~nm}$ and consists of ca. $75 \%$ anatase and $25 \%$ rutile.

The majority of the results reported here concern the PCO degradation of phenol. Phenol and phenols are present in many industrial wastewaters. In particular those arising from coke ovens, petroleum cracking and refining, surface coating preparation and engineering workshop operations. Phenol has been the subject of a number of detailed PCO research publications [4-8] and has been used in other studies where the PCO rates of a number of solutes have been determined under identical conditions[9-11]. Attention is focussed on the degradation and mineralization rates that can be obtained using various illumination sources, both natural and artificial, with the photocatalyst immobilized or freely suspended in various photoreactor arrangements. The effects of possible interfering species are considered and the mineralization rates that were obtained with real industrial wastewater matrices. Finally, the use of a novel photocatalytic total organic carbon analyzer in pollution control is outlined.

\section{DISCUSSION}

When PCO reactions are interrupted at only partial degradation of the parent contaminant, the same products are generally found as those formed in the radiolysis of aqueous, aerated solutions[12] where the $\mathrm{OH}$ radical is a primary reactant. In particular, hydroxylated products are generally identified. For example, the partial $P C O$ of benzoic acid yields $o-, m$ - and $p$-hydroxy benzoic acids [13] and the partial PCO of phenol yields hydroquinone, pyrocatechol, 1,2,4-benzenetriol, pyrogallol and 2-hydroxy 1,4-benzoquinone[4]. The origin of these products in terms of the generally accepted reaction mechanism for PCO is easy to understand. The absorption of bandgap light $(<380 \mathrm{~nm})$ by a $\mathrm{TiO}_{2}$ particle excites an electron to the conduction band and leaves a positive hole in the valence band:

$$
\mathrm{TiO}_{2} \frac{h v}{<380 \mathrm{~mm}}-\dot{c_{C B}}+\dot{h i}_{\mathrm{VB}}
$$

In the absence of interfering diversionary reactions this electron-hole pair will recombine. However, at least a portion of these charged species can migrate to the surface where various recombination delaying reactions can occur, eg.,

$$
\begin{aligned}
& \dot{c_{C B}}+O_{2(S)} \rightarrow \cdot O_{2(s)}^{-} \\
& \dot{h_{V B}}+O \bar{H}_{(S)} \rightarrow \cdot O H_{(S)}
\end{aligned}
$$

If organic species, $\mathrm{RH}$, are present in the water these will be attacked at the surface by the positive holes or the hydroxyl radicals. The possibility of attack of the organic solute in the bulk of the solution by freely diffusing $\mathrm{OH}$ radicals has also been raised [14]. Hydrogen abstraction reactions occur with some organics.

$$
\cdot \mathrm{OH}+\mathrm{RH} \rightarrow \mathrm{R} \cdot+\mathrm{H}_{2} \mathrm{O}
$$

In the case of aromatics or aliphatics containing unsaturated bonds, addition reactions also occur:

$$
\cdot \mathrm{OH}_{(S)}+\mathrm{RH} \rightarrow \cdot \mathrm{RHOH}
$$

Oxygen reacts with the organic free radicals to form peroxy radicals:

which give hydroxylated products:

$$
\cdot \mathrm{RHOH}+\mathrm{O}_{2} \rightarrow \cdot \mathrm{O}_{2} \mathrm{RHOH}
$$

$$
. \mathrm{O}_{2} \mathrm{RHOH} \rightarrow \mathrm{RHOH}+\mathrm{HO}_{2} \cdot
$$

If a surplus of oxygen is maintained and the reaction is allowed to continue, multiple hydroxylated products are formed in the case of aromatics and complete mineralization to $\mathrm{CO}_{2}$ occurs eventually.

The data in Fig. 1 show the temporal disappearance of phenol from an illuminated suspension of $0.1 \%$ $\mathrm{TiO}_{2}$, the appearance and disappearance of a hypothetical single intermediate and the appearance of $\mathrm{CO}_{2}$ calculated from measurements of the total organic carbon content of the suspension. The illumination source was a $100 \mathrm{~W}$ medium pressure mercury lamp located ca. $33 \mathrm{~cm}$ above an open dish containing $500 \mathrm{~mL}$ of the suspension [15]. The radiative output of this lamp at the photoactive wavelength of $365 \mathrm{~nm}$ was ca. $4 \mathrm{~W}$ but no attempt was made to maximize photon efficiency in this arrangement. The curves passing through the data points 


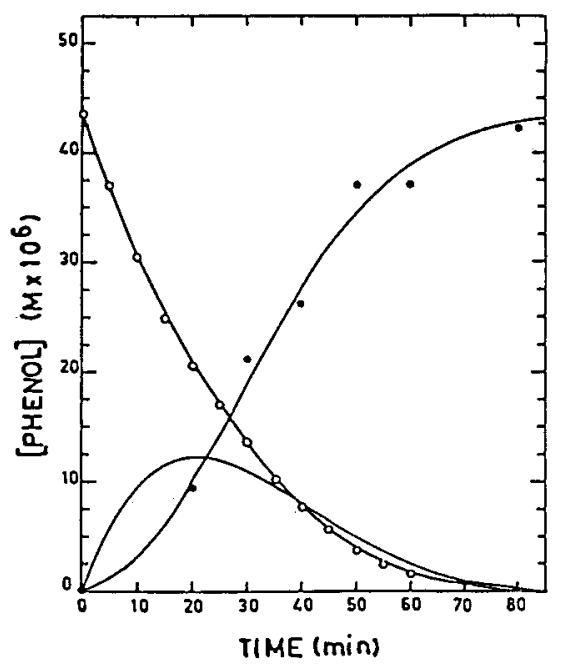

Fig.1.

Disappearance of pbenol, appearance of intermediate and

$\mathrm{CO}_{2}$ in phenol solution at $\mathrm{pH} 5.5$ containing $0.1 \% \mathrm{TiO}_{2}$

freely suspended, $100 \mathrm{~W}$ medium pressure mercury lamp;

O phenol concentration in solution,

- pbenol oxidized to $\mathrm{CO}_{2}$.

The lines were calculated by numerical integration of expressions (8)-(10)

were calculated by numerical integration of the differential equations:

$$
\begin{aligned}
& \frac{d[P]}{d t}=\frac{-k_{1} K_{1}[P]}{1+K_{1}[P]+K_{2}[I]} \\
& \frac{d[I]}{d t}=\frac{k_{1} K_{1}[P]-k_{2} K_{2}[I]}{1+K_{1}[P]+K_{2}[1]} \\
& \frac{d\left[C O_{2}\right]}{d t}=\frac{k_{2} K_{2}[I]}{1+K_{1}[P]+K_{2}[1]}
\end{aligned}
$$

where $[\mathrm{P}],[]$ and $\left[\mathrm{CO}_{2}\right]$ represent the concentrations of phenol, intermediate and $\mathrm{CO}_{2}$ respectively, $\mathrm{k}_{1}$ and $\mathrm{k}_{2}$ represent specific reaction rate constants for the formation of intermediate and $\mathrm{CO}_{2}$ respectively and $\mathrm{K}_{1}$ and $\mathrm{K}_{2}$ represent the equilibrium adsorption constants for phenol and intermediate respectively. From the viewpoint of a water treatment process the time and cost in converting a given fraction of the phenol to $\mathrm{CO}_{2}$ is of interest.

\section{Solar illumination}

Under a summer sun (12 February) at 34 degrees south the phenol degradation of $500 \mathrm{~mL}$ of $0.1 \% \mathrm{TiO}_{2}$ suspension proceeds at a significantly faster rate than wass obtained with the $100 \mathrm{~W}$ lamp. Destruction of $99 \%$ of the phenol, initially $100 \mu \mathrm{M}(9.4 \mathrm{ppm})$, occurred in an exposure of $80 \mathrm{~min}$. In the comparison with the $100 \mathrm{~W}$ lamp, the time required for $90 \%$ degradation of the phenol was 55 min, approximately 1.7 times less than with the $100 \mathrm{~W}$ lamp. However, much more efficient electrically-powered photoreactors can be constructed as discussed later.

The oxidation rates with direct sunlight approximately followed the Gaussian distribution pyrheliometer data for a clear "desert" sky from sunrise to sunset [16]. There was also a noticeable seasonal variation in the rates with the phenol destruction rate in mid-winter being $55 \%$ of the summer rate. Extensive solar irradiance data also show a marked seasonal variation in the $300 \mathrm{~nm} \cdot 400 \mathrm{~nm}$ solar flux [17].

\section{Immobilized catalyst}

The use of suspensions in photocatalysis requires the separation and recycling of the catalyst following oxidation of the organics in the contaminated water. In the case of ultrafine catalysts this may be a time consuming step. An alternative approach is to attach the catalyst to a transparent stationary support over which the contaminated water passes. Various supports have been used, the most inexpensive of which is sand.

The major disadvantage associated with the use of immobilized photocatalysts is the photon-wasting mass transfer limitation. This does not occur with fine particle suspensions since the solute molecule to semiconductor particle distance is always very small. The degradation rate for phenol at an initial concentration of $100 \mu \mathrm{M}$, circulated at $250 \mathrm{~mL} / \mathrm{min}$ in the free suspension was ca. 3 times faster than that with the catalyst immobilized on sand. Much greater disparities will be obtained at low flow rates and deep layers of solution; less for high flow rates and shallow layers as in transparent illuminated packed columns [18]. Turbulent flow through the reactor instead of laminar flow should also improve the transfer.

Degussa $\mathrm{P}_{25} \mathrm{TiO}_{2}$ can be readily attached to glass and the inner walls of glass spirals. The arrangement shown in Fig. 2 was designed to enable the pumping of both liquid and air bubbles in a closed loop through a $\mathrm{TiO}_{2}$ coated spiral surrounding a $20 \mathrm{~W}$ blacklight blue fluorescent tube. 


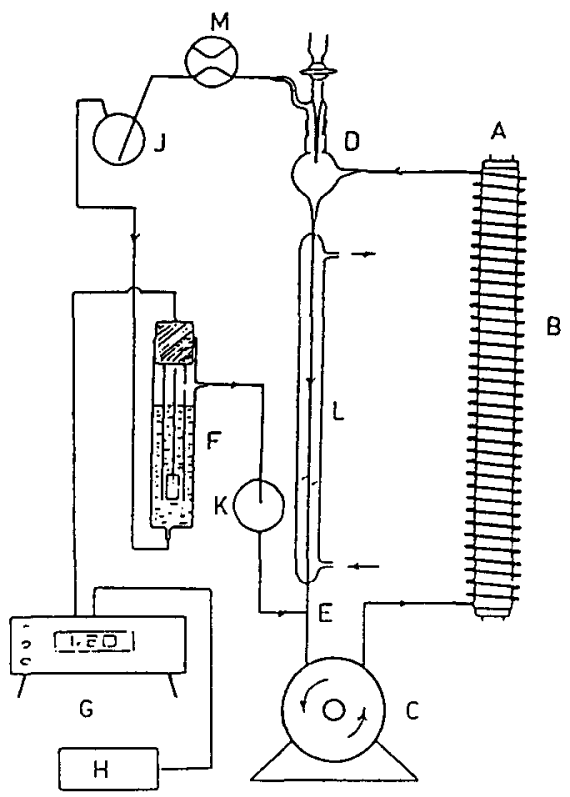

Fig. 2. Apparatus for $\mathrm{CO}_{2}$ determination with photocatalytic oxidation.

$\begin{array}{lllll}\text { A Fluorescent lamp } & \text { B } & \text { Glass spiral } & \text { C } & \text { Pump } \\ \text { D Loading port } & \text { E } & \text { Tee piece } & \text { F } & \text { Conductivity cell } \\ \text { G Conductivity meter } & \text { H } & \text { Computer } & \text { J.K } & \text { Traps } \\ \text { L Temperature-controlled } & & & \text { M } & \text { Four way tap }\end{array}$
water jacket

As the organic solute present in the water is oxidized to $\mathrm{CO}_{2}$ the air bubbles become enriched in $\mathrm{CO}_{2}$ and this is registered by a conductivity detector in the air loop. The rate of $\mathrm{CO}_{2}$ formation for a given solute at a given initial concentration is easy to measure in this apparatus. The relationship between the rate of $\mathrm{CO}_{2}$ formation $\mathrm{d}[\mathrm{S}] / \mathrm{dt}$, and solute concentration, [S], for all solutes measured was given by the expression:

$$
\frac{d[S]}{d t}=\frac{k_{1} K[S]}{1+K[S]}
$$

The constants $\mathrm{k}_{1}$ and $\mathrm{K}$ and the rates of $\mathrm{CO}_{2}$ formation at initial concentrations of solute of 1 and $50 \mathrm{mg} / \mathrm{L}$ determined for phenol and other solutes in this apparatus using a $40 \mathrm{~mL}$ solution volume are given in Table 1.

This Table summarises results reported in two publications $[10,11]$ by which it is possible to compare the rates obtained using freely suspended (f.s.) and immobilized (i) catalysts. The spirals used were similar but not identical; the immobilized catalyst was fixed to a $4 \mathrm{~mm}$ i.d. spiral and the freely suspended catalyst was contained in an uncoated $3 \mathrm{~mm}$ i.d. spiral. The mass transfer limitation would be accentuated by the use of the larger diameter spiral. Even so, the differences in rates at the $50 \mathrm{mg} / \mathrm{L}$ concentration are not pronounced. At the lower concentration of $1 \mathrm{mg} / \mathrm{L}$ the rates with the immobilized catalyst are ca. 50\% of those with the free suspension. In addition to the mass transfer limitation the accessibility of photoactive sites on the catalyst is another key factor. When immobilized, the catalyst will generally be present in a thin layer of conglommerate with less availability of photoactive sites than a free suspension. However, with careful design of the photoreactor it should be possible to minimize the efficiency differences between immobilized and freely suspended catalysts.

\section{Reactors with improved photon efficiency}

Great progress has been made in recent years in determining the families of organic compounds that are destroyed by photocatalytic oxidation and in identifying the intermediate degradation products [2]. The photoreactors used in many of these studies were primarily designed to facilitate sampling and analysis of products. Maximizing photon efficiency has been of minor or secondary importance. However, for the process to compete with or supplant existing water treatment technologies, attention needs to be given towards developing 1) catalysts with greater activity and 2) more photon efficient reactors. Since, for the most part, the photocatalyst suspensions used are of high opacity, thin annular or falling film reactors seem to be the most appropriate. The arrangement of a thin annular reactor was used with both $15 \mathrm{~W}$ Germicidal (output at $254 \mathrm{~nm}$ ) and $15 \mathrm{~W}$ blacklight fluorescent lamps (output max at $350 \mathrm{~nm}$ ) to determine the rates of degradation and mineralization of phenol [19]. For phenol at an initial concentration of $1 \mathrm{mM}$ a mineralization rate of $820 \mathrm{ppm}$ TOC/L/kWh was determined using the blacklight fluorescent tube, ca. 13 times more photon efficient than the concentration-corrected rate obtained for the results shown in Fig. 1. When the illumination was provided by $254 \mathrm{~nm}$ radiation from the $15 \mathrm{~W}$ germicidal lamp the phenol degradation rate was ca. twice that obtained using the blacklight fluorescent tube. 
TABLE 1 COMPARISON BETWEEN OXIDATION RATES USING FREELY SUSPENDED AND IMMOBIUZED CATALYSIS

Solute (S)

\begin{tabular}{|c|c|c|c|c|c|}
\hline & & $\begin{array}{c}K \\
(\mathrm{~L} / \mathrm{mg})\end{array}$ & $\begin{array}{c}k_{1} \\
(\mathrm{mg} / \mathrm{L} / \mathrm{min})\end{array}$ & $1^{*}$ & $50^{\star}$ \\
\hline \multirow[t]{2}{*}{ Benzoic acid } & $(f . s .)^{\bullet}$ & 0.082 & 8.2 & 0.62 & 6.58 \\
\hline & $(i)^{b}$ & 0.038 & 8.1 & 0.30 & 5.33 \\
\hline \multirow[t]{2}{*}{ Salicylic acid } & (f.s.) & 0.074 & 8.6 & 0.59 & 6.79 \\
\hline & (i) & 0.036 & 11.3 & 0.39 & 7.26 \\
\hline \multirow[t]{2}{*}{ Phend } & (f.s.) & 0.072 & 7.2 & 0.48 & 5.63 \\
\hline & (i) & 0.024 & 10.2 & 0.24 & 5.56 \\
\hline \multirow[t]{2}{*}{ 2-Chlorophenol } & (f.s.) & 0.050 & 10.1 & 0.48 & 7.21 \\
\hline & (i) & 0.010 & 18.4 & 0.18 & 6.13 \\
\hline \multirow[t]{2}{*}{ 4-Chlorphend } & (f.s.) & 0.045 & 10.1 & 0.43 & 6.96 \\
\hline & (i) & 0.038 & 10.2 & 0.37 & 6.68 \\
\hline \multirow[t]{2}{*}{ Nitrobenzene } & (f.s.) & 0.060 & 8.1 & 0.45 & 6.05 \\
\hline & (i) & 0.062 & 4.7 & 0.27 & 3.55 \\
\hline \multirow[t]{2}{*}{ Methanol } & (f.s.) & 0.048 & 9.1 & 0.42 & 6.44 \\
\hline & (i) & 0.014 & 11.5 & 0.16 & 4.73 \\
\hline \multirow[t]{2}{*}{ Ethanol } & (f.s.) & 0.038 & 9.0 & 0.33 & 5.87 \\
\hline & (i) & 0.021 & 10.1 & 0.21 & 5.17 \\
\hline \multirow[t]{2}{*}{ Acetic acid } & (f.s.) & 0.028 & 14.0 & 0.38 & 8.17 \\
\hline & (i) & 0.027 & 7.9 & 0.20 & 4.50 \\
\hline \multirow[t]{2}{*}{ Formic acid } & (t.s.) & 0.026 & 29.4 & 0.74 & 16.6 \\
\hline & (i) & 0.017 & 21.4 & 0.35 & 9.7 \\
\hline
\end{tabular}

\section{Inhibitors}

The preceding results were obtained using phenol and other solutes in pure water. These conditions would seldom be encountered in the real world. Normally, other species in addition to the primary pollutant will be present in significant concentration. Sulfate and phosphate, even at millimolar concentrations decrease oxidation rates by $20-70 \%$. Chloride ions also have an inhibiting effect on the oxidation rate in mildly acid solutions. Nitrate and perchlorate ions have insignificant effects [20]. The presence of other organics may also have an inhibiting effect as a consequence of competitive adsorption and reaction with the oxidizing radicals at the catalyst sites $[21,22]$.

\section{Industrial wastewaters}

Industrial wastewaters from a petroleum refinery and from a paint stripping operation were tested. The water from the oil refinery was comparatively low in organic content $(<10 \mathrm{ppm})$ but contained appreciable concentrations of aluminium and chloride ions. When spiked with $100 \mathrm{ppm}$ phenol the $\mathrm{PCO}$ rate for $\mathrm{CO}_{2}$ formation was $40 \%$ less than for $100 \mathrm{ppm}$ phenol in pure water.

The water from the paint stripping operation contained 9.3 parts per thousand TOC and $1220 \mathrm{ppm}$ phenols. The inorganic composition was unknown. Extended oxidation with both $\mathrm{UV} / \mathrm{H}_{2} \mathrm{O}_{2}$ and photocatalysis essentially freed the water from organics and residual $\mathrm{H}_{2} \mathrm{O}_{2}$. When the matrix was spiked with $100 \mathrm{ppm}$ phenol the $\mathrm{PCO}$ rate to $\mathrm{CO}_{2}$ was only $10 \%$ less than that in pure water. It is therefore apparent that in evaluating the efficiency of PCO, or any other treatment, for the destruction of organics in a particular wastewater each wastewater needs to be considered separately.

\section{TOC (total organic carbon) analysis}

As far as pollution of water supplies with organics is concerned the measurement of biochemical oxygen demand $(B O D)$ is required by most regulatory authorities. Unfortunately this norrnally takes 5 days for a result and is of little value as a real time control parameter. Chemical oxygen demand (COD) and total organic carbon 
(TOC) can be determined in 2 hours and a few minutes respectively and will reflect the BOD. The TOC determination is therefore most useful as a control parameter for the handling and treatment of organically polluted aqueous streams. Total organic carbon analyzers have been comparatively expensive scientific instruments and consequently have not been utilized to their full potential in presenving the environment. The fact that PCO is a powerful wet oxidation comparable to UV/persulfate but that it may be powered by long wavelength UV that is transmitted by glass confers advantages over conventional photolytic TOC analyzers. Less expensive materials can be used in constructing the photoreactor with attendant cost savings. Laboratory photocatalytic TOC analyzers have been in use for several years [23] and a commercial instrument is scheduled for release at a significantly lower price than conventional instruments.

\section{CONCLUSIONS}

Photocatalytic oxidation with $\mathrm{TiO}_{2}$ catalyst is of equivalent oxidizing power to $\mathrm{OH}$ radical reactions in aqueous solution. The reaction may be driven by electrically powered U.V. or natural solar U.V. To destroy organic pollutants in water with the formation of harmiess mineral products. The catalyst may be used in free suspension or immobilized and PCO rates in both configurations are reported. Phenol mineralization rates are given for both artificial and natural U.V. The effect of common inhibitors is discussed and the rates of phenol oxidation to $\mathrm{CO}_{2}$ in two industrial wastewater matrices are given. A novel application of PCO is in the field of total organic carbon analysis and a new low cost instrument has been manufactured. This and the use of photocatalysis in water purification provide new tools for preserving the environment.

Acknowledgements Part of this work was supported by a grant from the Australian Land and Water Resources Research and Development Corporation.

\section{REFERENCES}

1. Shaub W.M. and Tsang W. Environ. Sci. Technol. 17, 721-730 (1983).

2. Pelizzetti, E., Minero C. and Maurino V. Adv. Colloid Interfac Sci. 32, 271-316 (1990).

3. Ollis, D.F., Pelizzeti E. and Serpone N. Environ. Sci. Technol. 25, 1523-1529 (1991).

4. Okamoto K.-J., Yamamoto Y., Tanaka H., Tanaka M. and Itaya A. Bull. Chem. Soc. Jpn. $\underline{58}$, 2015-2022 (1985).

5. Augugliaro V., Palmisano L. and Sclafani A. Toxicol, and Environ. Chem. 16, 89-109 (1988).

6. Augugliaro V., Davi E., Palmisano L., Schiavello M. and Sclafani A. Appl. Catal. 65, 101-116 (1990).

7. Sclafani A., Palmisano L. and Davi E. J. Photochem. and Photobiol. A. Chem. $\underline{56}, 113-123$ (1991).

8. Wei T.-Y., Wang Y.-Y. and Wan C.C. J. Photochem. and Photobiol A. Chem. 55, 115-126 (1990).

9. Marthews R.W. Wat. Res. 20, 569-578 (1986).

10. Matthews R.W. J. Catal. 111, 264-272 (1988).

11. Matthews R.W. Wat. Res. 24, 653-660 (1990).

12. Mao Y., Schöneich C. and Asmus K.-D.J. Phys. Chem. 95, 10080-10089 (1991).

13. Matthews R.W. J. Chem. Soc. Faraday Trans. 1, $\underline{80}, 457-471$ (1984).

14. Turchi C.S. and Ollis D.F. J. Catal. 122, 178-192 (1990).

15. Matthews R.W. and McEvoy S.R. J. Photochem. and Photobiol. A. Chem. (in press).

16. Meinel A.B. and Meinel M.P. 'Applied Solar Energy' Addison-Wesley, Reading, Massachusetts, 1976 p.63.

17. Leifer A. "The Kinetics of Environmental Aquatic Photochemistry, Theory and Practice" ACS Professional Reference Book, 1988, p261.

18. Matthews R.W. J. Catal. 113, 549-555 (1988).

19. Matthews R.W. and McEvoy S.R. J. Photochem. and Photobiol. A. Chem. (submitted).

20. Abdullah M., Low G.K.-C. and Matthews R.W. J. Phys. Chem. 94, 6820-6825 (1990).

21. Matthews R.W. J. Chem. Soc. Chem. Commun. 177-179 (1983).

22. Turchi C.S. and Ollis D.F. J. Catal. 119, 483-496 (1989).

23. Matthews R.W., Abdullah M. and Low G.K.-C. Anal. Chim. Acta 233 171-179 (1990). 